\title{
Impact of evolving strategy on clinical outcomes and central pulmonary artery growth in patients with bilateral superior vena cava undergoing a bilateral bidirectional cavopulmonary shunt
}

\author{
Osami Honjo, MD, PhD, ${ }^{\mathrm{a}}$ Kim-Chi D. Tran, MD,${ }^{\mathrm{a}}$ Zhongdong Hua, MD,${ }^{\mathrm{b}}$ Priya Sapra, ${ }^{\mathrm{a}}$ \\ Abdullah A. Alghamdi, MD, ${ }^{\mathrm{a}}$ Jennifer L. Russell, MD, ${ }^{\mathrm{a}}$ Christopher A. Caldarone, MD, ${ }^{\mathrm{a}}$ and \\ Glen S. Van Arsdell, MD
}

\begin{abstract}
Objective: We reported a high incidence of thrombosis, central pulmonary artery hypoplasia, and mortality for bilateral bidirectional cavopulmonary shunts. We hypothesized that technical modifications in the cavopulmonary anastomosis and anticoagulation would limit thrombus and central pulmonary artery hypoplasia, and thereby improve outcomes.
\end{abstract}

\begin{abstract}
Methods: Sixty-one patients (median age, 8.4 months; weight, $6.6 \mathrm{~kg}$ ) underwent bilateral bidirectional cavopulmonary shunt from 1990 to 2007. The cohort was divided into 2 groups: 1) the conventional group (1990-1999, $\mathrm{n}=37$ ) and 2) the V-shaped group, with a hemi-Fontan or modification in which the cavae were anastomosed to the pulmonary artery adjacent to each other so they formed the appearance of a V (1999-2007, $n=24)$. Central and branch pulmonary artery growth, survival, and reinterventions were determined.
\end{abstract}

\begin{abstract}
Results: The pre-Fontan study showed equivalent superior venae cavae and Nakata indices. The central pulmonary artery index and central pulmonary artery/Nakata index ratio were significantly higher in the V-shaped group $(P<.05)$. There were no differences in freedom from death or transplant (conventional $69 \%$ vs V-shaped $75 \%$ at 3 years, $P=.5)$, and a nonsignificant trend toward improving freedom from reinterventions $(63 \%$ vs $81 \%$ at 3 years, $P=.15)$ and thrombosis ( $82 \%$ vs $95 \%$ at 1 year, $P=.11)$ was observed in the $\mathrm{V}$-shaped group. Multivariate analysis showed anastomotic strategy, low saturation, and thrombosis were predictors for death. Anastomotic strategy, lack of anticoagulation, thrombosis, and small superior venae cavae were predictors for reintervention $(P<.05)$. Predictors for thrombus included small superior venae cavae, Nakata index, and low saturation $(P<.03)$.
\end{abstract}

Conclusions: Surgical modifications for bilateral bidirectional cavopulmonary shunts were associated with the larger central pulmonary artery size. Lack of anticoagulation and anastomotic strategy affected reintervention. Anastomotic strategy and postoperative thrombus affected mortality. (J Thorac Cardiovasc Surg 2010;140:522-8)

Supplemental material is available online.

Earn CME credits at

http://cme.ctsnetjournals.org

Systemic venous abnormalities were, at one time, exclusion criteria for staged single-ventricle palliation. ${ }^{1}$ Along with

\footnotetext{
From The Labatt Family Heart Centre, ${ }^{\text {a }}$ The Hospital for Sick Children, and the University of Toronto, Toronto, Ontario, Canada; and Department of Cardiovascular Surgery, ${ }^{\mathrm{b}}$ Beijing Fuwai Hospital, Beijing, China.

Disclosures: None.

Read at the Thirty-fifth Annual Meeting of the Western Thoracic Surgical Association, June 24-27, 2009, Banff, Alberta, Canada.

Received for publication June 19, 2009; revisions received March 29, 2010; accepted for publication April 12, 2010; available ahead of print July 12, 2010.

Address for reprints: Glen S. Van Arsdell, MD, Division of Cardiovascular Surgery, Hospital for Sick Children, 555 University Avenue, Toronto, Ontario, Canada, M5G 1X8 (E-mail: glen.vanarsdell@sickkids.ca).

$0022-5223 / \$ 36.00$

Copyright $(2) 2010$ by The American Association for Thoracic Surgery doi:10.1016/j.jtcvs.2010.04.036
}

improvement in overall management strategy, increasing clinical experience has shown the feasibility of singleventricle palliation in patients with systemic venous abnormalities, including bilateral superior vena cava $(\mathrm{SVC}){ }^{2,3}$ Nonetheless, the presence of bilateral SVC, which occurs in up to $15 \%$ of patients with single-ventricle physiology, ${ }^{4}$ still poses technical challenges at the time of bilateral bidirectional cavopulmonary shunt (BCPS). Small SVC size and unfavorable flow characteristics in the central branch pulmonary arteries (PAs) may compromise BCPS patency, central PA growth, and subsequent clinical outcomes.

Our previous study showed that bilateral BCPS was associated with central PA hypoplasia, thrombosis, and a high mortality. ${ }^{5}$ On the basis of those findings, we made 2 major modifications in the management of patients with a single ventricle and bilateral SVC. As a strategy to limit stasis in the central PA, the bilateral BCPS anastomoses are made immediately adjacent to each other on the central PA. This gives a V-shaped appearance to the bilateral BCPS on an angiogram. If the $\mathrm{V}$ strategy cannot be used because of anatomic issues of aortic size or a small individual SVC size, a hemi-Fontan is performed on 1 side. The other 


$$
\begin{aligned}
& \text { Abbreviations and Acronyms } \\
& \begin{array}{ll}
\mathrm{BCPS} & =\text { bidirectional cavopulmonary shunt } \\
\mathrm{BSA} & =\text { body surface area } \\
\mathrm{CVP} & =\text { central venous pressure } \\
\mathrm{NS} & =\text { not significant } \\
\mathrm{PA} & =\text { pulmonary artery } \\
\mathrm{SaO}_{2} & =\text { arterial saturation } \\
\mathrm{SVC} & =\text { superior vena cava } \\
\mathrm{TAPVD} & =\text { total anomalous pulmonary venous } \\
& \text { drainage }
\end{array}
\end{aligned}
$$

modification is routine use of systemic anticoagulation. We hypothesized that these modifications in management strategy may provide better central PA growth, less thrombosis in the cavopulmonary system, and potentially improve clinical outcomes. This follow-up study reviewed our 18-year experience of evolving surgical strategy, focusing on central PA growth, and the impact of the new strategy on survival, reintervention, and thrombosis.

\section{MATERIALS AND METHODS}

We reviewed all patients who had undergone staged single-ventricle palliation between January 1990 and December 2007 in The Hospital for Sick Children, Toronto. The Research Ethics Board at the Hospital for Sick Children approved the study and waived the requirement for patient consent. Sixty-one patients underwent bilateral BCPS in the study period. The entire cohort was divided into 2 groups: the conventional group $(n=37$, 1990-1999, conventional anastomosis with limited postoperative anticoagulation) and V-shaped group ( $\mathrm{n}=24,1999-2007$, V-shaped anastomosis or hemi-Fontan with routine postoperative anticoagulation). Pre-BCPS characteristics are shown in Table 1.

\section{Surgical Technique}

A BCPS was performed under mild hypothermic cardiopulmonary bypass and standard bicaval cannulation. A central venous pressure (CVP) monitoring line was routinely inserted into the right internal jugular vein. The right SVC was routinely cannulated, typically with a $12 \mathrm{~F}$ right-angle venous cannula, unless the patient had a dominant left SVC with a small right SVC. The left SVC was cannulated if the size of the left SVC was equivalent to or larger than that of the right SVC or a high CVP or decrease in cerebral oxygen saturation based on near-infrared spectroscopy was noted with left SVC tourniquet occlusion. In general, we now cannulate only the dominant SVC. The BCPS anastomosis or PA plasty was usually performed under an on-pump beating heart state. Bilateral PA patch plasty with autologous pericardium was typically performed before the BCPS anastomosis (Figure 1, A). Silk retraction sutures were placed on both sides of the ascending aorta to assist with visualization of the central PAs (Figure 1, B,C). Three patients had division of the aorta to achieve adequate exposure. In those instances, cardioplegic cardiac arrest was used. Cardioplegic arrest was used for those in whom a hemi-Fontan type procedure was chosen or there was a need for intracardiac procedures, such as atrial septectomy and repair of anomalous pulmonary veins or atrioventricular valve. Circulatory arrest was used on a few occasions to achieve adequate surgical field visualization. The cavopulmonary connection was created in a standard end-to-side manner. The left BCPS was usually done first (Figure 1, B,C). The anastomotic technique evolved to the following: The posterior wall of the SVC was anastomosed to the branch PA using
7-0 or 6-0 polypropylene sutures (Ethicon, Inc, Somerville, NJ) as a continuous suture. The anterior aspect of the anastomosis was achieved with an interrupted suture technique using 7-0 or 6-0 polypropylene sutures. If a systemic-to-pulmonary shunt was previously placed, the SVC was anastomosed to the shunt-insertion site provided it was centrally located on the PA. If there was antegrade blood flow from a ventricle through the main PA, the main PA was divided and the pulmonary valve was oversewn under cardioplegic cardiac arrest.

\section{Anticoagulation}

There was no specific protocol for anticoagulation before 1999. The majority of the patients $(>80 \%)$ in the conventional group were not anticoagulated. After 1999, we changed to routine anticoagulation. In the V-shaped anastomosis group, the patients undergoing bilateral BCPS were routinely anticoagulated. Continuous infusion of unfractionated heparin was started within 24 hours after surgery, which was subsequently switched to lowmolecular-weight heparin $(85 \%)$ or aspirin $(15 \%)$. Uniform use of lowmolecular-weight heparin began in 2004 at a dosage of $1 \mathrm{mg} / \mathrm{kg}$ every 12 hours. Adjustment of dosage was used to achieve anti-Xa levels of 0.5 and $1.0 \mathrm{U} / \mathrm{mL}$. Anticoagulation monitoring was done weekly during hospitalization and monthly thereafter. Low-molecular-weight heparin was continued until the time of the Fontan procedure. Patients routinely received warfarin therapy after the Fontan operation until their fenestration was closed.

\section{Evaluation of Central Pulmonary Artery Growth}

Angiograms and hemodynamic measurements on cardiac catheterizations were reviewed. The diameters of right and left PAs were measured at the hilum just proximal to the takeoff of the branching vessels in the anterior posterior projection. The Nakata index was calculated as the summation of the right and left PA cross-sectional areas indexed to the patient's body surface area (BSA). ${ }^{6}$ Diameters of the right SVC at pre-BCPS catheterization were measured just above the veno-atrial junction where the anastomosis was supposed to be made. Diameters of the left SVC at pre-BCPS catheterization were measured just above the point where the left SVC crossed the left PA. Diameters of the SVCs at pre-Fontan catheterization were measured at approximately $5 \mathrm{~mm}$ above the BCPS anastomosis. The combined SVC index was calculated as the summation of the right and left SVC cross-sectional areas indexed to the patient's BSA. The SVC size relative to the PA size before BCPS was evaluated with an SVC/Nakata index ratio achieved by combining the SVC index and dividing it by the Nakata index. Diameters of the central branch PAs at pre-Fontan catheterization were measured at the mid point between the internal margins of bilateral SVC anastomoses. The central PA index was calculated as the central PA cross-sectional area indexed to the patient's BSA. The central PA growth relative to the branch PA growth at the hilum distal to the BCPS anastomosis was evaluated with the central PA/Nakata index ratio, where the central PA index was divided by the Nakata index.

\section{Reintervention and Thrombosis}

Reintervention was defined as a subsequent surgical or catheter-based procedure on either SVC or branch PA. Interventions unrelated to the bilateral BCPS, such as coil embolization for nonspecific collaterals, were excluded. Thrombus was usually initially identified by echocardiography and subsequently verified by computed tomography or angiography. Thrombus was considered significant if it was present in the cavopulmonary shunt system (ie, bilateral SVCs or branch PAs).

\section{Statistical Analysis}

Data are presented as mean \pm standard deviation. Differences between groups were analyzed by the Mann-Whitney $U$ test or unpaired $t$ test. Frequencies of the events between the groups were tested by the chi-square test. Freedom from death, reintervention, or thrombosis was analyzed using the Kaplan-Meier survival analysis, and survival was compared between the groups with a log-rank test. Regression analysis of the entire cohort was 
TABLE 1. Comparison of preoperative characteristics between conventional and V-shaped anastomosis groups

\begin{tabular}{|c|c|c|c|}
\hline & $\begin{array}{c}\text { Conventional } \\
(\mathbf{n}=37)\end{array}$ & $\begin{array}{c}\text { V-shaped } \\
(\mathrm{n}=\mathbf{2 4})\end{array}$ & $\begin{array}{c}P \\
\text { value }\end{array}$ \\
\hline Age (mo) & $\begin{array}{l}30 \pm 42 \\
\quad(\text { median, 11.4) }\end{array}$ & $\begin{array}{l}10 \pm 14 \\
\quad(\text { median, } 7.2)\end{array}$ & $<.001$ \\
\hline Body weight (kg) & $\begin{array}{l}11.7 \pm 11.8 \\
\quad(\text { median, } 7.9)\end{array}$ & $\begin{array}{l}6.5 \pm 2.5 \\
\quad(\text { median, } 6.3)\end{array}$ & .005 \\
\hline $\operatorname{BSA}\left(\mathrm{m}^{2}\right)$ & $\begin{array}{l}0.49 \pm 0.27 \\
\quad(\text { median, } 0.44)\end{array}$ & $\begin{array}{l}0.36 \pm 0.07 \\
\quad(\text { median, } 0.37)\end{array}$ & .017 \\
\hline \multicolumn{4}{|l|}{ Diagnosis } \\
\hline Right isomerism & 7 & 3 & \\
\hline AVSD & 4 & 1 & \\
\hline DORV & 3 & 1 & \\
\hline Pulmonary atresia & 1 & 1 & \\
\hline Left isomerism & 3 & 4 & \\
\hline Pulmonary atresia & 2 & 2 & \\
\hline AVSD & 1 & 2 & \\
\hline HLHS & 3 & 5 & \\
\hline Unbalanced AVSD & 9 & 2 & \\
\hline DORV & 5 & 6 & \\
\hline DILV & 3 & 1 & \\
\hline 1-TGA & 2 & 0 & \\
\hline Tricuspid atresia & 1 & 1 & \\
\hline $\begin{array}{l}\text { Single ventricle } \\
\quad \text { (undetermined) }\end{array}$ & 3 & 2 & \\
\hline Multiple VSDs & 1 & 0 & \\
\hline Previous Norwood & 5 & 4 & \\
\hline $\mathrm{SaO}_{2}(\%)$ & $\begin{array}{l}71.6 \pm 5.3 \\
\quad(\text { median, } 70)\end{array}$ & $\begin{array}{l}79.2 \pm 4.3 \\
\quad(\text { median, } 79)\end{array}$ & .14 \\
\hline Hemoglobin (g/dL) & $\begin{array}{l}152 \pm 22 \\
\quad(\text { median, 155) }\end{array}$ & $\begin{array}{l}145 \pm 30 \\
\quad(\text { median, 153) }\end{array}$ & .07 \\
\hline
\end{tabular}

$A V S D$, Atrioventricular septal defect; $B S A$, body surface area; $D O R V$, double-outlet right ventricle; $H L H S$, hypoplastic left heart syndrome; DILV, double-inlet left ventricle; $T G A$, transposition of the great arteries; VSD, ventricular septal defect; $\mathrm{SaO}_{2}$, arterial saturation.

used to determine independent variables of risk for the end points of freedom from death/transplant, reintervention, and thrombosis.

\section{RESULTS}

The conventional group was older $(P<.001)$ and had a larger body size at the time of bilateral BCPS $(P<.05$ for body weight and BSA; Table 1). Diagnosis was comparable between the groups.

\section{Baseline Cavopulmonary Anatomy and Physiology}

At pre-BCPS catheterization, the conventional group had larger SVC diameters, especially the left SVC diameter compared with the $\mathrm{V}$-shaped group $(P<.05)$. The PA diameters tended to be larger in the conventional group $(P<.05$ for right PA diameter and indexed left PA diameter; Table 2). The larger sizes seen in the conventional group were proportional to patient size as demonstrated by the comparable combined SVC, Nakata, and SVC/Nakata indices. The mean PA pressure and ventricular end-diastolic pressure were similar between groups $(P=$ not significant $[\mathrm{NS}])$.

\section{Bilateral Bidirectional Cavopulmonary Shunt}

There were no differences in cardiopulmonary bypass, aortic crossclamp time, frequency of aortic crossclamp, or left SVC cannulation between the groups $(P=\mathrm{NS}$; Table E1). Postoperative CVP and arterial saturation $\left(\mathrm{SaO}_{2}\right)$ were comparable between the groups $(P=\mathrm{NS})$. There were 5 $(13.5 \%)$ hospital mortalities in the conventional group, whereas there was no hospital mortality in the V-shaped group ( $P=\mathrm{NS}$ to .06). Two hospital deaths were clearly related to PA or SVC thrombosis/occlusion. Two patients had sudden cardiac arrest in the intensive care unit during the immediate postoperative period, and resuscitation was not successful. One patient required a central shunt because of profound desaturation after BCPS and died after central shunt placement.

\section{Pulmonary Artery Growth After Bilateral Bidirectional Cavopulmonary Shunt}

Figure 2 shows representative angiograms of patients with a V-shaped anastomosis $(A, B)$ and a conventional anastomosis $(C, D)$. At pre-Fontan catheterization (Table 3), there was a larger indexed left SVC diameter in the conventional group $(P=.03)$. The absolute branch PA diameters were larger in the conventional group than in the $\mathrm{V}$-shaped group $(P<.01)$, mainly because of a larger BSA in the conventional group $(P=.002)$. The central PA index $(P=P .04)$ and central PA/Nakata index ratio $(P=.002)$ were significantly larger in the V-shaped group compared with those in the conventional group. Pulmonary arterioplasty did not affect the central PA index or the central PA/Nakata ratio in either group $(P=\mathrm{NS})$. No difference was noted in the $\mathrm{SVC}$ pressure between the groups $(P=\mathrm{NS})$.

\section{Survival}

There were no differences in freedom from death or transplant (conventional vs V-shaped, $75 \%$ vs $86.7 \%$ at 1 year, $69.4 \%$ vs $75.6 \%$ at 3 years, $P=.5$, Figure 3 ). In the conventional group, there were $4(10.8 \%)$ late deaths: pulmonary vascular disease after Fontan operation in 1 patient, thrombotic occlusion of central PA late after BCPS in 1 patient, and unknown cause in 2 patients. Another 2 patients required transplantation. In the $\mathrm{V}$-shaped group, there were $3(12.5 \%)$ late deaths: sepsis in 2 patients and thrombotic occlusion of a Fontan conduit in 1 patient. Another patient required transplantation.

Univariate analysis of all patients revealed that high postoperative CVP $(P=.05)$, low postoperative $\mathrm{SaO}_{2}(P=.01)$, SVC/PA thrombosis $(P=.02)$, and total anomalous pulmonary venous drainage (TAPVD) $(P=.03)$ were predictors for death or transplantation. Independent predictors of death or transplantation in the multivariate analysis were anastomotic strategy $(P=.04)$, low postoperative $\mathrm{SaO}_{2}$ $(P=.02)$, and SVC/PA thrombosis $(P=.03)$. 


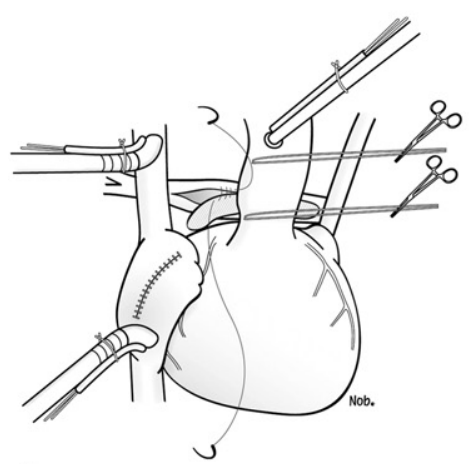

A

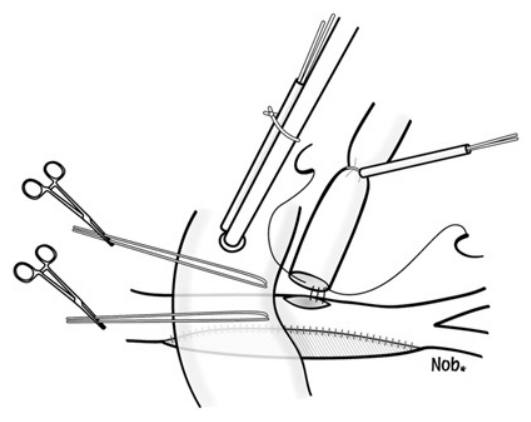

B

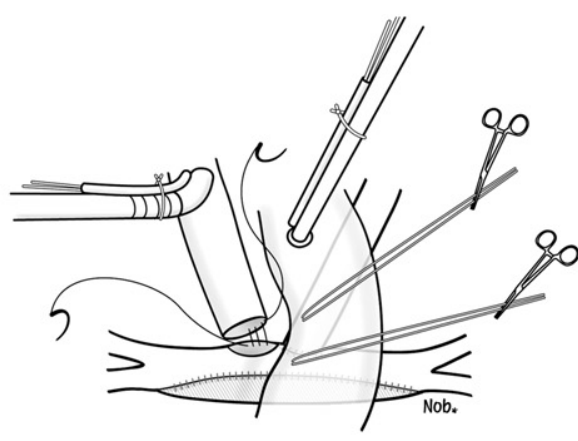

C

FIGURE 1. A, Bilateral PA plasty with an autologous pericardial patch is typically performed in an on-pump beating heart state. The bilateral BCPS is subsequently performed. The aorta is fully mobilized and retracted rightward to visualize the central PA. B, The left BCPS is performed first. Only the larger of the 2 SVCs usually is cannulated. Intermittent decompression or separate cannulation can be performed if the SVC pressure is elevated more than 20 mm Hg. C, Right BCPS is subsequently performed. The aorta is retracted leftward. The bilateral BCPS anastomoses almost touch each other or are a few millimeters apart behind the aorta.

\section{Factors Related to Reintervention}

There was a nonsignificant trend toward higher freedom from all reinterventions in the $\mathrm{V}$-shaped group (conventional vs V-shaped; $78 \%$ vs $81 \%$ at 1 year, $63 \%$ vs $81 \%$ at 3 years, $P=.15$, Figure 2). Fifteen patients $(40 \%)$ had a total of 19 reinterventions in the conventional group: 5 reoperations (thrombosis of central PA in 3 patients, occlusion/stenosis of BCPS anastomosis in 2 patients) and 12 catheter-based reinterventions (BCPS anastomosis in 7 patients, central PA in

TABLE 2. Comparisons of anatomic measurements at pre-bidirectional cavopulmonary shunt cardiac catheterization between conventional and V-shaped anastomosis groups

\begin{tabular}{|c|c|c|c|}
\hline & $\begin{array}{l}\text { Conventional } \\
\quad(\mathbf{n}=\mathbf{3 7})\end{array}$ & $\begin{array}{l}\text { V-shaped } \\
(n=24)\end{array}$ & $\begin{array}{c}P \\
\text { value }\end{array}$ \\
\hline Right SVC diameter (mm) & $6.1 \pm 2.7$ & $4.8 \pm 1.4$ & .12 \\
\hline Left SVC diameter (mm) & $6.2 \pm 2.1$ & $5.8 \pm 1.1$ & .025 \\
\hline Dominant right SVC & $25 / 37(67 \%)$ & $15 / 24(62 \%)$ & \\
\hline $\begin{array}{l}\text { Indexed right SVC } \\
\text { diameter }\left(\mathrm{mm} / \mathrm{m}^{2}\right)\end{array}$ & $35.6 \pm 41.6$ & $19.6 \pm 13.9$ & .09 \\
\hline $\begin{array}{l}\text { Indexed left SVC } \\
\text { diameter }\left(\mathrm{mm} / \mathrm{m}^{2}\right)\end{array}$ & $34.2 \pm 24.2$ & $27.7 \pm 11.6$ & .009 \\
\hline $\begin{array}{l}\text { Combined SVC index } \\
\left(\mathrm{mm}^{2} / \mathrm{m}^{2}\right)\end{array}$ & $157.6 \pm 111.8$ & $151.1 \pm 45.2$ & .12 \\
\hline Right PA diameter (mm) & $9.3 \pm 4.8$ & $7.2 \pm 2.1$ & .039 \\
\hline Left PA diameter $(\mathrm{mm})$ & $8.1 \pm 3.2$ & $6.8 \pm 1.9$ & .19 \\
\hline McGoon ratio & $1.86 \pm 0.57$ & $2.15 \pm 0.66$ & .67 \\
\hline $\begin{array}{l}\text { Indexed right PA diameter } \\
\qquad\left(\mathrm{mm} / \mathrm{m}^{2}\right)\end{array}$ & $86.9 \pm 103.8$ & $44.5 \pm 27.7$ & .2 \\
\hline $\begin{array}{l}\text { Indexed left PA diameter } \\
\qquad\left(\mathrm{mm} / \mathrm{m}^{2}\right)\end{array}$ & $59.6 \pm 52.8$ & $39.7 \pm 22.44$ & .054 \\
\hline Nakata index $\left(\mathrm{mm}^{2} / \mathrm{m}^{2}\right)$ & $250.7 \pm 114.9$ & $282.3 \pm 137$ & .86 \\
\hline SVC/Nakata index ratio & $0.68 \pm 0.46$ & $0.69 \pm 0.52$ & .38 \\
\hline Mean PA pressure $(\mathrm{mm} \mathrm{Hg})$ & $13.8 \pm 5.2$ & $14.2 \pm 4.4$ & .67 \\
\hline $\begin{array}{l}\text { Ventricular end-diastolic } \\
\text { pressure }(\mathrm{mm} \mathrm{Hg})\end{array}$ & $7.7 \pm 4.8$ & $8.0 \pm 3.6$ & .53 \\
\hline
\end{tabular}

4 patients, branch PA in 1 patient). All 5 reoperations were related to early or late mortality. Four patients $(16 \%)$ in the V-shaped group had reinterventions. Two patients required reoperation after catheter-based intervention for total occlusion of central PA and severe bilateral BCPS anastomotic stenosis, respectively. Another 2 patients required balloon angioplasty for BCPS anastomotic stenosis.

The univariate analysis of all patients showed that small pre-BCPS McGoon $(P=.01)$ and Nakata $(P=.03)$ indices, SVC/PA thrombosis $(P=.01)$, TAPVD $(P=.03)$, and previous Norwood palliation $(P=.03)$ were predictors for reinterventions. Multivariate analysis revealed that anastomotic strategy $(P=.02)$, lack of anticoagulation $(P=.02)$, surgery before $1995(P=.01)$, younger age $(P=.03)$, small body weight and BSA $(P<.05$ for both $)$, TAPVD $(P=.05)$, thrombosis in an SVC or central PA $(P=.02)$, and small SVC index $(P=.03)$ were predictors for reintervention.

\section{Factors Related to Superior Vena Cava/Pulmonary Artery Thrombus}

There was a nonsignificant trend toward higher freedom from SVC and PA thrombus in the V-shaped group (conventional, $82 \%$ vs $\mathrm{V}$-shaped, $95 \%$ at 1 year, $P=.11$ ). Univariate analysis of all patients showed that anastomotic strategy $(P=.001)$, lack of anticoagulation $(P=.01)$, surgery before $1995(P=.001)$, right atrial isomerism $(P=.02)$, and small McGoon and Nakata indices $(P=.01$ for both) were predictors for postoperative SVC/PA thrombosis. Independent predictors of SVC/PA thrombus in the multivariate analysis were younger age $(P=.03)$, small body weight and BSA $(P<.05$ for both $)$, small SVC $(P=.001)$, small Nakata in$\operatorname{dex}(P=.03)$, and low $\mathrm{SaO}_{2}$ after bilateral BCPS $(P=.002)$.

\section{DISCUSSION}

Patients with bilateral SVCs undergoing a bilateral BCPS have associated anatomic and physiologic challenges. The 


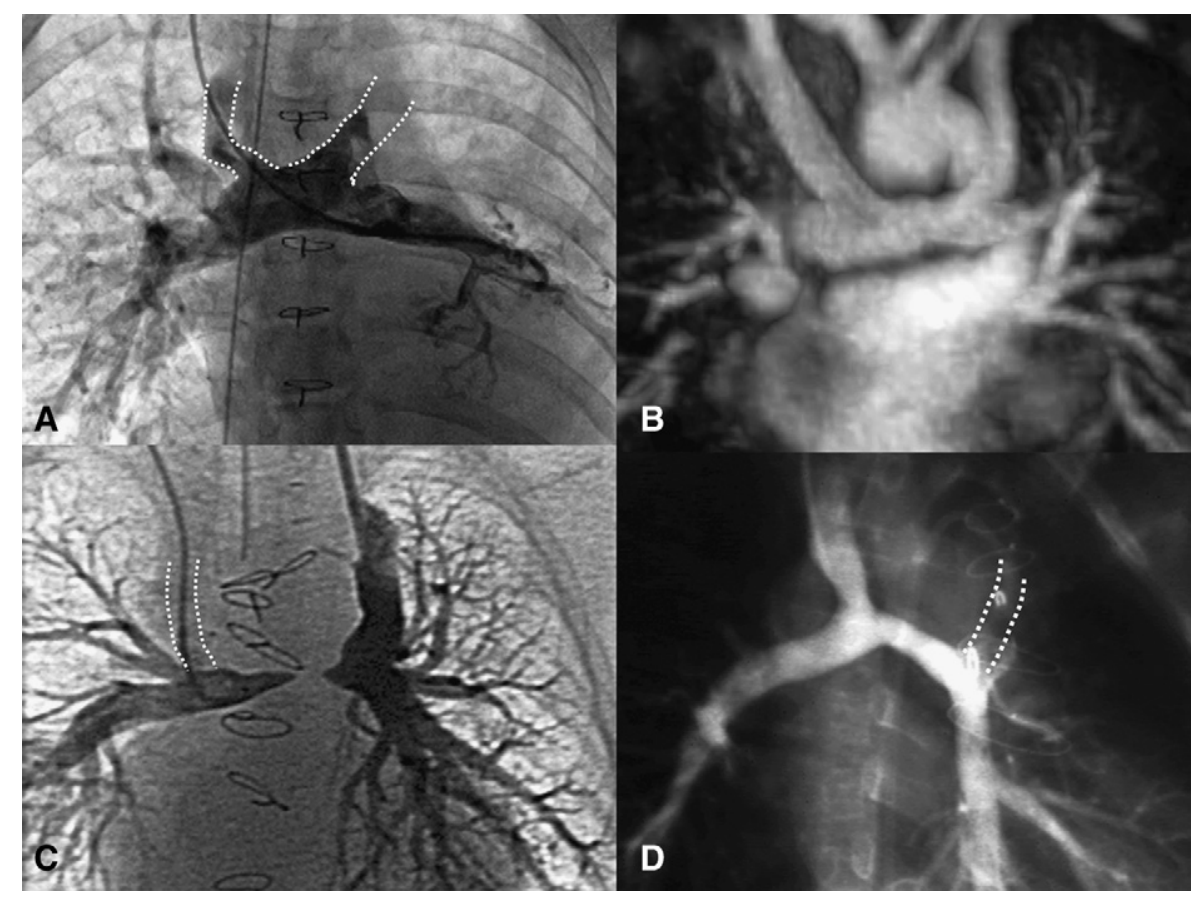

FIGURE 2. Angiograms and magnetic resonance imaging of bilateral BCPS. A, V-shaped anastomosis with adequate central PA growth. B, V-shaped anastomosis with a limited distance between bilateral SVC anastomosis (magnetic resonance imaging). C, Central PA occlusion in conventional group. The anastomosis between the SVC and PA had a right angle, leaving a wide central PA portion. D, Long-segment central PA hypoplasia in conventional group.

technical issues in anastomosing relatively small SVCs, combined with less blood flow in each SVC, may raise the risk of stenosis, thrombus, and low saturations. Minor steno-

TABLE 3. Branch pulmonary artery growth and superior vena cava diameters at pre-Fontan catheterization between conventional and V-shaped anastomosis groups

\begin{tabular}{lccc}
\hline & $\begin{array}{c}\text { Conventional } \\
(\mathbf{n}=\mathbf{2 7})\end{array}$ & $\begin{array}{c}\text { V-shaped } \\
(\mathbf{n}=\mathbf{1 7})\end{array}$ & $\begin{array}{c}\boldsymbol{P} \\
\text { value }\end{array}$ \\
\hline BSA $\left(\mathrm{m}^{2}\right)$ & $0.68 \pm 0.31$ & $0.55 \pm 0.11$ & .002 \\
Right SVC diameter $(\mathrm{mm})$ & $7.4 \pm 3.5$ & $7.5 \pm 2.1$ & .31 \\
Left SVC diameter $(\mathrm{mm})$ & $7.9 \pm 3.3$ & $7.8 \pm 1.8$ & .2 \\
$\quad$ Indexed right SVC diameter & $53.3 \pm 63.3$ & $48.3 \pm 27.7$ & .44 \\
$\quad\left(\mathrm{~mm} / \mathrm{m}^{2}\right)$ & & & \\
$\quad$ Indexed left SVC diameter & $58.2 \pm 44.9$ & $51.4 \pm 22.9$ & .03 \\
$\quad\left(\mathrm{~mm} / \mathrm{m}^{2}\right)$ & & & \\
Combined SVC index & $146.8 \pm 90.1$ & $184.5 \pm 74.8$ & .69 \\
$\quad\left(\mathrm{~mm}{ }^{2} / \mathrm{m}^{2}\right)$ & & & \\
Right PA diameter $(\mathrm{mm})$ & $10.2 \pm 4.1$ & $7.9 \pm 1.3$ & .007 \\
Left PA diameter $(\mathrm{mm})$ & $9.6 \pm 3.5$ & $7.9 \pm 1.3$ & .003 \\
Indexed right PA diameter & $15.9 \pm 7.0$ & $16.9 \pm 6.9$ & .4 \\
$\quad\left(\mathrm{~mm} / \mathrm{m}^{2}\right)$ & & & \\
Indexed left PA diameter & $15.6 \pm 5.5$ & $15.1 \pm 4.1$ & .15 \\
$\quad\left(\mathrm{~mm} / \mathrm{m}^{2}\right)$ & & & \\
Central PA diameter $(\mathrm{mm})$ & $7.3 \pm 4.0$ & $8.2 \pm 3.3$ & .4 \\
Central PA index $\left(\mathrm{mm}{ }^{2} / \mathrm{m}^{2}\right)$ & $76.5 \pm 73$ & $116.8 \pm 88$ & .042 \\
Nakata index $\left(\mathrm{mm}{ }^{2} / \mathrm{m}^{2}\right)$ & $259 \pm 144$ & $232 \pm 101$ & .928 \\
Central PA/Nakata index ratio & $0.28 \pm 0.16$ & $0.53 \pm 0.33$ & .002 \\
SVC pressure $(\mathrm{mm} \mathrm{Hg})$ & $12.4 \pm 4.9$ & $10.3 \pm 3.7$ & .112 \\
\hline
\end{tabular}

$B S A$, Body surface area; $P A$, pulmonary artery; $S V C$, superior vena cava. sis at an anastomotic site may therefore result in more serious consequences. For a conventional bilateral BCPS, blood flow from each SVC preferentially flows into the ipsilateral lung vasculature, that is, the BCPS flow has a limited bidirectional component, leaving the central PA as a low or no-flow region. Thrombus, central PA hypoplasia, or occlusion may occur. Our previously published experience ${ }^{5}$ identified that conventionally managed bilateral cavae in functionally univentricular hearts were problematic. There was a high rate of significant thrombus or thrombosis, poor central PA growth, significant reintervention, and mortality. ${ }^{5}$ Thrombus was associated with a small intervening segment of the PA between the bilateral BCPSs and markedly differing sizes between each SVC. Thrombus was highly correlated with mortality. We designed the V-shaped surgical strategy and medical anticoagulation strategy to address these issues. The present analysis assesses whether the interventional changes affected outcomes. Specifically, (1) was the central PA problem improved, (2) was the incidence of thrombus and thrombotic complications altered, and (3) was there an improvement in overall freedom from death or transplantation?

\section{Impact on Central Pulmonary Artery}

The higher central PA/Nakata index ratio $(0.28$ vs 0.52 , $P=.002$ ) seen in the $\mathrm{V}$-shaped group (Table 2) shows that the surgical modification provided a larger central PA size compared with the conventional strategy. Most had 


\section{Freedom from death or transplantation}

\section{Freedom from reintervention}
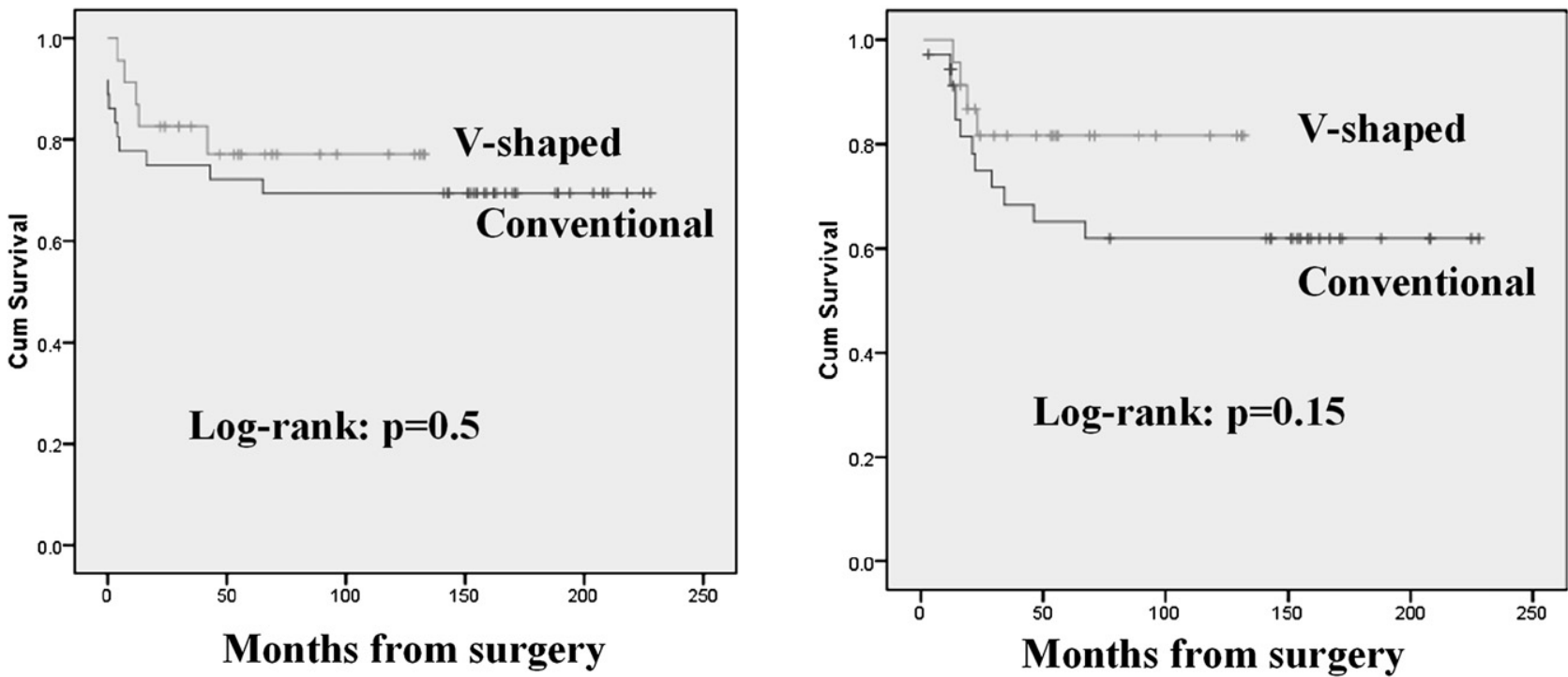

FIGURE 3. Kaplan-Meier survival analysis of freedom from death or transplantation (left) and freedom from reintervention (right) between conventional and V-shaped groups.

PA augmentation arterioplasty, which raises the possibility that the larger central PA is entirely related to augmentation. Analyzed as an individual variable, PA arterioplasty was not a predictor of PA size in either group. This finding indicates that flow patterns are likely important for central PA growth (or shrinking) characteristics and that a strategy aimed to promote flow in the central portion of the PA is beneficial. The concept is further supported by a recent publication on computational fluid dynamic simulations in which Amodeo and colleagues ${ }^{7}$ showed that that there was little flow in the central portion of the PA for widely separated bilateral BCPSs and good flow in the central portion when the bilateral BCPSs were brought together on the central PA.

\section{Impact on Thrombus and Thrombotic Complications}

The impact of anticoagulation on thrombotic complications can be difficult to verify with this sample size. Since we routinely started anticoagulation, 1 patient has had occlusion of the central PA. This was identified 6 months after the bilateral BCPS in a situation in which the distance between the bilateral BCPS anastomosis was more than usual. The large aorta affected the ability to create the V-shaped appearance. A better strategy for this patient would likely have been a hemi-Fontan on 1 side to ensure that there was flow in the most central portion of the PA (ie, we interpret this as technical failure as opposed to a conceptual failure).

Univariate analysis of all patients showed that the change in surgical strategy and anticoagulation were correlated with less SVC/PA thrombus. By group analysis, the V-shaped group showed a nonsignificant trend toward freedom from thrombosis at 1 year $(95 \%$ vs $82 \%, P=.11)$. Analysis of all patients showed that the independent predictors of SVC/PA thrombus/thrombosis were small patient size, small SVC size, small Nakata index, and poor postoperative $\mathrm{SaO}_{2}$. By combining all the noted factors, one can surmise that patient factors related to size (BSA, SVC size, PA size) are important factors in risk for thrombus. It seems that surgical strategy is also important but not as strong a factor as patient-related factors. Notably, PA patch arterioplasty had no negative or positive correlation with thrombus/thrombosis. Given the multivariable findings, one would suggest that delaying a bilateral BCPS until the patient is a larger size (if medically appropriate) may be beneficial. On univariate analysis, a combination of the V-shaped strategy and anticoagulation was beneficial.

\section{Impact on Reintervention}

Although the central PA hypoplasia can be overcome by surgical modification of flow characteristics, there is still a technical challenge in anastomosing relatively small bilateral SVCs. The left SVC anastomosis can be particularly challenging in the presence of a large heart and aorta. A manifestation of the technical challenge is the fact that half of all reinterventions in this series specifically were related to the BCPS anastomosis. Independent markers of need for reintervention were anastomotic strategy, SVC/PA thrombosis, and lack of anticoagulation. Other items of significance were small weight/age and a small SVC. These findings also indicate that a larger patient size might be beneficial and that unfavorable outcomes of thrombosis and reintervention can be affected by surgical and medical strategy that change coagulation and flow characteristics. 


\section{Impact on Survival}

Occlusion or significant thrombus in the central PA or BCPS anastomosis is clearly related to morbidity and mortality. The descriptive analysis showed that there was no early death related to an SVC/PA problem in the V-shaped anastomosis group, whereas 3 operative deaths $(8 \%)$ were directly related to SVC/PA thrombosis in the conventional group $(P=.15)$. The multivariate predictors of death or transplantation were anastomotic strategy, SVC/PA thrombosis, and low postoperative $\mathrm{SaO}_{2}$. When the 2 groups were analyzed as cohorts, the difference in survival was not statistically significant. This can be explained by patient attrition that is seen in the V-shaped group, well out of the need for hospitalization.

\section{Other Potential Strategies}

Little has been written about the surgical issues of functionally single ventricles and bilateral cavae. It has been suggested that maintenance of an antegrade ventriculo-pulmonary blood flow would allow adequate central PA growth in patients undergoing bilateral BCPS with a risk of central PA hypoplasia. ${ }^{4,8}$ We agree that the flow characteristics in the central PA would be improved with associated antegrade blood flow. A large proportion of the patient group, including patients with pulmonary atresia or hypoplastic left heart syndrome after the Norwood procedure, do not have this as an option. There are also potential disadvantages, such as insufficient ventricular volume loading, chylothorax, ${ }^{9}$ and prolonged pleural drainage.

Amodeo and Di Donato ${ }^{10}$ recently described a unifocal anastomosis of the 2 SVCs with a subsequent single pathway anastomosis to the PA. Conceptually, the strategy also holds promise for limiting thrombosis issues and PA growth problems because it mandates bidirectional flow in the PAs. The applicability across the anatomic spectrum will need to be established.

The hemi-Fontan also seems to be effective in minimizing the problems of a conventional bilateral BCPS. The disadvantage is that it requires cardioplegic cardiac arrest. Our findings were that the technique was valuable when an individual SVC was particularly small. The advantage of making a PA connection without having to directly circumferentially anastomose the small SVC to the PA may be important. The hemi-Fontan technique was used in 2 patients $(8 \%)$ included in the V-shaped group but likely should have been used in a few more patients in whom the aorta was large and precluded bringing the tips of the SVCs close together.

\section{Study Limitations}

Limitations include the retrospective nature of the study using histologic controls. The basic strategy in treating patients with a single ventricle in the 1990s differs from the current strategy. This is seen in the patients' baseline characteristics, such as age at surgery and body weight (older and larger in the conventional group). This may be reflected in the less favorable early outcomes seen in the conventional group. Although the V-shaped anastomosis and hemiFontan type procedure have been performed for the same purpose (ie, to maintain adequate central PA blood flow), these 2 procedures may result in different central PA growth and subsequent clinical outcomes. The surgical modification and anticoagulation strategies were initiated at a similar time. This precludes defining if there were separate effects on thrombosis and clinical outcomes.

\section{CONCLUSIONS}

Surgical modifications for bilateral BCPS in patients with bilateral SVCs were associated with the larger central PA size. Cavopulmonary circuit thrombus was correlated with death/transplantation and reintervention. Anastomotic strategy correlated with death. There was a univariate association of anastomotic strategy and anticoagulation to SVC/PA thrombus. Anastomotic strategy and anticoagulation both affected reintervention risk in a multivariable model. Patient size affected thrombus formation and reintervention. When medically appropriate, operating on larger patients and using a surgical strategy to promote central PA flow and a strategy of medical anticoagulation would be rational.

The authors thank Cori Atlin for assistance in manuscript preparation and Nobuko Yamamoto for illustrations.

\section{References}

1. Choussat A, Fontan F, Besse P, Vallot F, Chauve A, Bricaud H. Selection criteria for Fontan's procedure. In: Anderson RH, Shinebourne EA, eds. Pediatric Cardiology. Edinburgh: Churchill Livingstone; 1977:559-66.

2. McElhinney DB, Reddy VM, Moore P, Hanley FL. Bidirectional cavopulmonary shunt in patients with anomalies of systemic and pulmonary venous drainage. Ann Thorac Surg. 1997;63:1676-84.

3. Azakie A, Merklinger SL, Williams WG, Van Arsdell GS, Coles JG, Adatia I. Improving outcomes of the Fontan operation in children with atrial isomerism and heterotaxy syndromes. Ann Thorac Surg. 2001;72:1636-40.

4. Gandy K, Hanley F. Management of systemic venous anomalies in the pediatric cardiovascular surgical patient. Semin Thorac Cardiovasc Surg Pediatr Card Surg Annu. 2006;63-74.

5. Iyer GK, Van Arsdell GS, Dicke FP, McCrindle BW, Coles JG, Williams WG. Are bilateral superior vena cavae a risk factor for single ventricle palliation? Ann Thorac Surg. 2000;70:711-6.

6. Nakata S, Imai Y, Takanashi Y, Kurosawa H, Tezuka K, Nakazawa M, et al. A new method for the quantitative standardization of cross-sectional areas of the pulmonary arteries in congenital heart diseases with decreased pulmonary blood flow. J Thorac Cardiovasc Surg. 1984;88:610-9.

7. Amodeo A, Grigioni M, Gagliardi MG, Del Gaudio C, Morbiducci U, D'Avenio G, et al. Improved management of systemic venous anomalies in a single ventricle: new rationale. J Thorac Cardiovasc Surg. 2009;138:1154-9.

8. Reddy VM, McElhinney DB, Moore P, Haas GS, Hanley FL. Outcomes after bidirectional cavopulmonary shunt in infants less than 6 months old. J Am Coll Cardiol. 1997;29:1365-70.

9. Frommelt MA, Frommelt PC, Berger S, Pelech AN, Lewis DA, Tweddell JS, et al. Does an additional source of pulmonary blood flow alter outcome after a bidirectional cavopulmonary shunt? Circulation. 1995; 92(Suppl):II240-4.

10. Amodeo A, Di Donato RM. The unifocal bilateral bidirectional cavopulmonary anastomosis. Ann Thorac Surg. 2007;84:2134-5. 
TABLE E1. Operative variables between conventional and V-shaped anastomosis groups

\begin{tabular}{lccc}
\hline & $\begin{array}{c}\text { Conventional } \\
(\mathbf{n}=\mathbf{3 7})\end{array}$ & $\begin{array}{c}\text { V-shaped } \\
(\mathbf{n}=\mathbf{2 4})\end{array}$ & $\begin{array}{c}\boldsymbol{P} \\
\text { value }\end{array}$ \\
\hline CPB (min) & $137 \pm 53$ & $134 \pm 52$ & .84 \\
Off-pump BCPS & 2 & 1 & \\
Aortic crossclamp (min) & $65 \pm 52$ & $51 \pm 40$ & .7 \\
Aortic crossclamp & 11 & 14 & \\
Left SVC cannulation & 6 & 6 & \\
$\mathrm{CVP}$ (mm Hg) & $16.7 \pm 5.2$ & $16.8 \pm 2.9$ & .3 \\
$\mathrm{SaO}_{2}(\%)$ & $78.6 \pm 9.7$ & $78.7 \pm 7.2$ & .25 \\
Hospital mortality & 5 & 0 & .06 \\
Concomitant procedures & & & \\
PA plasty & 16 & 6 & \\
DKS anastomosis & 2 & 4 & \\
TAPVD repair & 1 & 4 & \\
AV valve repair & 1 & 1 & \\
Central shunt & 2 & 0 & \\
Lung biopsy & 2 & 0 & \\
Subaortic ridge resection & 2 & 0 & \\
Hybrid stage II & 0 & 1 & \\
\hline$B C P S$, Bidirectional cavopulmonary shunt; $C P B$, cardiopulmonary bypass; $C V P$, cen- \\
tral venous pressure; $D K S$, Damus-Kaye-Stansel; $P A$, pulmonary artery; Sa $o_{2}$, arterial \\
saturation; $T A P V D$, total anomalous pulmonary venous drainage; $A V$, atrioventricular. \\
\end{tabular}

